by Kannaluik. An estimate can be made of the thermal conductivity by using the WeidemannFranz relationship, since it is probable that the Lorenz ratio for scandium is similar to that of the early members of the rare earth series, that is, around $2.7 \times 10^{-8}$ c.g.s. units. On this basis, the thermal conductivity of scandium would be 0.027 cal. cm./ cm. ${ }^{2}$ sec. deg. C., at room temperature.

In the X-ray diffraction studies, using a $19-\mathrm{cm}$. high-temperature powdor camera, scandium was examined at temperatures up to $850^{\circ} \mathrm{C}$. The filings had been sealed in a thin-walled silica tube under vacuum but even so at a temperature of $750^{\circ} \mathrm{C}$. the lines of scandium oxide appeared on the film. No attempt was made to take photographs above $850^{\circ} \mathrm{C}$. because of the limitations of furnace power and the rapidly increasing strength of the oxide lines.

The structure remained hexagonal close-packed throughout the temperature range employed. The values of the lattice parameters and of the axial ratio are shown in Fig. 2; the behaviour is very similar to that of many of the rare earths ${ }^{2}$, the $c$ parameter increasing more rapidly than the $a$ parameter at low temperatures, while at high temperatures the rate of increase of the parameters is comparable so that the axial ratio becomes approximately constant. A least-squares fitting of the experimontal points gives the following velues for the instantaneous coefficients of thermal expansion :

$$
\begin{gathered}
a=\left(5 \cdot 6_{8}+1 \cdot 3_{7} t\right) \cdot 10^{-6} /^{\circ} \mathrm{C} . \\
c=\left(12 \cdot 7_{5}+0 \cdot 5_{7} t\right) \cdot 10^{-6} /^{\circ} \mathrm{C} .
\end{gathered}
$$

where $t$ is the temperature (deg. C.). Thus the values for temperatures of $100^{\circ} \mathrm{C}$., $500^{\circ} \mathrm{C}$., and $800^{\circ} \mathrm{C}$. are $7 \cdot 1,12 \cdot 5$ and $16 \cdot 6 \times 10^{-8} / \mathrm{deg}$. C., for $\alpha_{a}$ and $13 \cdot 3$, 15.6 and $17.3 \times 10^{-8} / \mathrm{deg}$. C. for $\alpha_{c}$.

$$
\begin{aligned}
& \text { P. G. Mardon } \\
& \text { J. L. NiChols } \\
& \text { J. H. PEarce } \\
& \text { D. M. Poole }
\end{aligned}
$$

Plutonium Metallurgy Group,

Atomic Energy Research Establishment, Harwell.

'Spedding, F. H., Deane, A. M., Wakefleld, G., and Dennison, D. H., Trans. Met. Soc. A.I.M.E., 218 (4), 608 (1960).

${ }^{2}$ Aschneidner, jun., K. A., A Compilation of the Physical Properties of the Rare Earth, Scardium and Ytrium Metals (to be pablished)

Ball, J. G., Lee, J. A., Mardon, P. G., and Robertson, J. A. I., Mem. Scr. de Rev. de Met., 5\%, 1, 49 (1960).

\section{Control of Irradiation Embrittlement in Molybdenum}

IroN, steel, and other body-centred cubic metals show an increase in ductile-brittle transition tempera. ture as a result of neutron irradiation. In an attempt to elucidate the mechanism of this embrittlement for EN2 steel, Hull and Mogford ${ }^{1}$ studied the effect of nentron irradiation on the parameters $\sigma_{i}$ and $k_{y}$ in the Petch relation :

$$
\sigma_{y}=\sigma_{i}+k_{y^{d-1 / 2}}
$$

where $\sigma_{y}$ is the yield stress and $2 d$ the grain diameter. They found that $\sigma_{i}$, the lattice friction stress, increased, but $k_{y}$, which is a measure of the strength of dislocation locking, remained constant. They interpreted this to mean that the embrittlement was caused by point defects or groups of defects which impeded the movement of slip dislocations in their glide planes. This simple phenomenological description of irradiation embrittlement enables changes in ductile-brittle transition temperature caused by irradiation to be predicted from Cottrell's brittle fracture criterion ${ }^{2}$ :

$$
\left(\sigma_{i} d^{1 / 2}+k_{y}\right) k_{y} \geqslant \beta \mu \gamma
$$

once $\sigma_{i}$ has been measured as a function of integrated neutron flux.

Johnson ${ }^{3}$ has applied a similar method to that of Hull and Mogford in studying the irradiation embrittlement of molybdenum. His results showed that the embrittloment mochanism in molybdenum is more complex than for $E N 2$ steel, and in interpreting his results Johnson suggested that in pure metals the point defects created during irradiation cause dislocation climb. It follows that the effect of irradiation on the mechanical properties of a pure metal such as molybdenum should depend on the density and distribution of dislocations in the metal before irradiation.

In an initial attempt to observe this expected dependence of irradiation embrittlement on dislocation density and distribution, experiments have been performed on molybdenum with two different types of dislocation structures. The first type of material was heavily cold-worked by swaging and the second typo heavily cold-worked and then stressrelieved at $1,000^{\circ} \mathrm{C}$. for $\frac{1}{2} \mathrm{hr}$. to give a fine substructure. The starting material in each case was Murex sintered molybdenum containing nominally 50-100 p.p.m. carbon, 50 p.p.m. iron, 20 p.p.m. oxygen, 10 p.p.m. hydrogen, and 5 p.p.m. nitrogen. Both materials were machined into Hounsfield type tensile specimens and four batches of ten specimens of each were irradiated in Bepo for $3,6,9$ and 12 months respectively at a temperature of $40-50^{\circ} \mathrm{C}$. The corresponding integrated epithermal neutron fluxes were about $1,2,3$ and $4 \times 10^{19}$ n.v.t. The ductile-brittle transition temperatures of the unirradiated materials and of each of these eight batches of irradiated specimens were measured using a modified Hounsfield tensometer operating at a strain rate of $0.88 \times 10^{-4}$ sec. $^{-1}$.

The ductile-brittle transition temperature of each batch was taken to be the highest temperature at which no appreciable plastic deformation occurred before fracture. On this criterion the transition temperature for both types of materials was $+120 \pm$ $10^{\circ} \mathrm{C}$. both before and after irradiation. Moreover, irradiation did not influence the shape of the loadelongation curve at any temperature. The transition temperature of recrystallized specimens of the same batch of molybdenum was $-60 \pm 10^{\circ} \mathrm{C}$.

These results indicate that at least some measure of control of the irradiation embrittlement of body. centred cubic transition metals can be achieved by using materials with controlled dislocation structures. A fuller account and discussion of these results is to be published elsewhere.

This work was initiated under a U.S. Navy Depart. ment Contract and in its later stages was financed by the U.K. Atomic Fnergy Authority and Central Electricity Generating Board. It was carried out under the general direction of Prof. J. G. Ball.
D. N. Sethra
A. A. JoHNSON
K. J. Proud
S. S. SHEININ

Metallurgy Department,

Imperial College of Science and Technology, London, S.W.7.

${ }^{1}$ Hull, D., and Mogford, I. L., Phil. Mag., 3, 1213 (1958).

'Cottrell, A. H., Trans. Amer. Inst. Mech. Eng., 212, 192 (1958).

a Johnson, A. A., Phil. Mag.. 5, 413 (1960). 